\title{
Airway inflammation, airway responsiveness and cough before and after inhaled budesonide in patients with eosinophilic bronchitis
}

\author{
C.E. Brightling, R. Ward, A.J. Wardlaw, I.D. Pavord
}

\begin{abstract}
Airway inflammation, airway responsiveness and cough before and after inhaled budesonide in patients with eosinophilic bronchitis. C.E. Brightling, R. Ward, A.J. Wardlaw, I.D. Pavord. C) ERS Journals Ltd 2000.

ABSTRACT: Eosinophilic bronchitis is a common cause of chronic cough, characterized by sputum eosinophilia similar to that seen in asthma, but unlike asthma the patients have no objective evidence of variable airflow obstruction or airway hyperresponsiveness. The reason for the different functional associations is unclear. The authors have tested the hypothesis that in eosinophilic bronchitis the inflammation is mainly localized in the upper airway.

In an open study the authors measured the lower (provocative concentration causing a $20 \%$ fall in forced expiratory volume in one second (PC20)) and upper (PC25 MIF50) airway responsiveness to histamine, lower and upper airway inflammation using induced sputum and nasal lavage, in 11 patients with eosinophilic bronchitis. The authors assessed changes in these measures and in cough reflex sensitivity to capsaicin and cough severity after $400 \mu \mathrm{g}$ of inhaled budesonide for 4 weeks.

A nasal eosinophilia was present in only three patients with one having upper airway hyperresponsiveness. Following treatment with inhaled corticosteroids the geometric mean sputum esinophil count decreased from $12.8 \%$ to $2.9 \%$ (mean difference 4.4-fold, $95 \%$ confidence interval (CI) $2.14-10.02$ ), the mean \pm SEM cough visual analogue score on a $100 \mathrm{~mm}$ scale decreased from $27.2 \pm 6.6 \mathrm{~mm}$ to $12.6 \pm 5.7 \mathrm{~mm}$ (mean difference 14.6, 95\% CI 9.1-20.1) and the cough sensitivity assessed as the capsaicin concentration required to cause two coughs $\left(C_{2}\right)$ and five coughs $\left(C_{5}\right)$ improved $\left(C_{2}\right.$ mean difference 0.75 doubling concentrations, 95\% CI $0.36-1.1 ; C_{5}$ mean difference 1.3 doubling concentration, $95 \%$ CI 0.6-2.1). There was a significant positive correlation between the fold change in sputum eosinophil count and doubling dose change in $C_{5}$ after inhaled budesonide $(r=0.61)$.

It is concluded that upper airway inflammation is not prominent in eosinophilic bronchitis and that inhaled budesonide improves the sputum eosinophilia, cough severity and sensitivity suggesting a causal link between the inflammation and cough. Eur Respir J 2000; 15: 682-686.
\end{abstract} \author{
Hospital, Leicester, UK. \\ Correspondence: C.E. Brightling \\ Dept of Respiratory Medicine \\ Glenfield Hospital \\ Groby Rd \\ Leicester \\ LE3 9QP \\ UK \\ Fax: 1162583950
}

Dept of Respiratory Medicine, Glenfield

Keywords: Cough

eosinophilic bronchitis

sputum

Received: August 91999

Accepted after revision December 131999

This study was supported by the Glenfield Research Fund and the Astra Foundation.
Eosinophilic bronchitis is a condition presenting with chronic cough and characterized by sputum eosinophilia like asthma, but unlike asthma the patients have no objective evidence of variable airflow obstruction or airway hyperresponsiveness [1,2]. The authors [3] and others [4] have shown that eosinophilic bronchitis is the cause of cough in $10-20 \%$ of patients presenting to a respiratory specialist. The reason for the different relationship between eosinophilic airway inflammation and disordered airway function in eosinophilic bronchitis compared with asthma is unknown. Patients with eosinophilic bronchitis commonly have upper airway symptoms [2, 3], so one possibility is that the inflammation is mainly localized to the upper airway. There is some evidence that the cough and sputum eosinophilia in patients with eosinophilic bronchitis improves with inhaled corticosteroids [2], arguing against predominant upper airway inflammation. However, no studies have examined the effect of inhaled corticosteroids on objective markers of cough sensitivity and it is not known whether the beneficial effects of in- haled corticosteroids are mediated through improvement in upper airway inflammation.

The authors have looked for direct and functional evidence of upper airway inflammation by measuring nasal lavage eosinophil count $[5,6]$ and extrathoracic airway responsiveness to histamine [6-8]. The authors have repeated the measures after 4 weeks treatment with inhaled budesonide and related changes in inflammation to objective changes in cough sensitivity.

Methods
Subjects
Eleven subjects were recruited from outpatient clinics
after presenting with an isolated chronic cough lasting $>3$
weeks from a group of 20 patients identified with eosino-
philic bronchitis. Four subjects had previously been invol-
ved in a study investigating the prevalence of eosinophilic
bronchitis, but the measurements in this study are indep-
endent of the previous report [3]. Subjects had a cough, no


symptoms suggesting variable airflow obstruction, normal spirometric values, normal peak expiratory flow (PEF) variability (maximum within day amplitude percentage mean $<20 \%$ over 2 weeks), a methacholine provocative concentration of histamine causing a $20 \%$ fall in forced expiratory volume in one second $\left(\mathrm{FEV} 1 ; \mathrm{PC}_{20}\right)>16 \mathrm{mg} \cdot \mathrm{mL}^{-1}$, a normal chest radiograph and a sputum eosinophilia $>3 \%$ nonsquamous cells (the authors' normal range $0-1 \%$ ). Subjects details at the time of diagnosis are illustrated in table 1 . The median time from diagnosis to entry into the study was 2 months. None had taken oral or inhaled corticosteroids for at least 1 month before entry into the study. The subjects gave full informed consent to participate in the study. The protocol was approved by the Leicestershire Health Authority ethics committee.

\section{Measurements}

Allergen skin sensitivity was measured by skin-prick testing to Dermatophagoides pteronyssinus, cat fur, grass pollen and Aspergillus fumigatus solutions, with normal saline and histamine controls (Bencard, Newark, Nottinghamshire, UK). Cough severity was rated on a $100 \mathrm{~mm}$ horizontal visual analogue scale (VAS) with 0 being no cough and 100 being worst cough ever. Cough sensitivity was assessed using the capsaicin cough challenge [9, 10]. Subjects inhaled at just below their functional residual capacity doubling concentrations of capsaicin $(0.5-500$ $\mu \mathrm{M})$ in a sequential order at 1-min intervals via a nebulizer attached to a breath-activated dosimeter delivering $8 \mu \mathrm{L}$. The number of coughs in response to each concentration was counted and recorded. The challenge was stopped when the concentration elicited $\geq 5$ coughs or the highest dose of capsaicin was reached.

Airway responsiveness was measured using the tidal breathing method [11]. Doubling concentrations of histamine $\left(0.03-16 \mathrm{mg} \cdot \mathrm{mL}^{-1}\right)$ were nebulized via a Wright

Table 1. - Characteristics of subjects at diagnosis

\begin{tabular}{lc}
\hline $\mathrm{N}$ & 11 \\
\hline Age* & $51(24)$ \\
Male & 6 \\
FEV1 \% pred & + \\
FEV1/FVC \% & \\
Methacholine PC20 <16 $\mathrm{mg} \cdot \mathrm{mL}^{-1}$ & $105 \pm 8$ \\
Atopy & $82 \pm 1.6$ \\
Rhinitis & 0 \\
Cough duration in months* & 3 \\
Current smokers & 7 \\
Pack-year history $>5$ & $25(30)$ \\
Sputum characteristics & 0 \\
Eosinophil count $\%{ }^{*}$ & 0 \\
Neutrophil count $\% *$ & \\
Macrophage count $\% *$ & $13.2(0.12)$ \\
Epithelial count $\% *$ & $52(37)$ \\
Lymphocyte count $\% *$ & $30(30)$ \\
Total cell count $\times 10^{*} \cdot \mathrm{mL}^{-1}$ of sputum & $3(3)$ \\
Viability \%* & $0(1)$ \\
Squamous cells $\% *$ & $2.05(0.07)$ \\
\hline
\end{tabular}

FEV1: forced expiratory volume in one second; FVC: forced vital capacity; PC20: provocative concentration of histamine causing a $20 \%$ in FEV1. ${ }^{*}$ : median (interquartile range); ${ }^{+}$: mean \pm SEM; ${ }^{\#}$ : geometric mean $(\log$ SEM). nebulizer (a gift from Fisons, Leicestershire, UK). Histamine was used in preference to methacholine as upper airway hyperresponsiveness has only been demonstrated using histamine. Patients inhaled through a mouthpiece during tidal breathing for 2 min. FEV1 and maximal midinspiratory flow (MIF50) was measured 30 and $90 \mathrm{~s}$ after each inhalation using a rolling seal spirometer. The challenge was stopped either after a $>20 \%$ fall in FEV1 or a maximal dose of histamine $\left(16 \mathrm{mg} \cdot \mathrm{mL}^{-1}\right)$ was reached.

Sputum was induced and processed as previously described $[12,13]$. Briefly sputum was induced using 3,4 and $5 \%$ saline inhaled in sequence for $5 \mathrm{~min}$ via an ultrasonic nebulizer (Medix, Harlow, Essex, UK; output $0.9 \mathrm{~mL} \cdot \mathrm{min}^{-1}$; mass median diameter $\left.5.5 \mu \mathrm{m}\right)$. After each inhalation patients blew their noses and rinsed their mouths to minimize nasal contamination and expectorated sputum into a sterile pot. FEV1 was measured after each inhalation and subjects were pretreated with inhaled salbutamol $200 \mu \mathrm{g} 10 \mathrm{~min}$ before sputum induction to minimize bronchoconstriction. Sputum free from salivary contamination was selected and dispersed using $0.1 \%$ dithiothrietol (DTT) and a differential cell count was obtained by counting $>400$ nonsquamous cells on a Romanowski stained cytospin.

Nasal lavage was obtained by instilling $5 \mathrm{~mL}$ of normal saline into each nostril, with the subjects head extended and their soft palate closed [6]. After $10 \mathrm{~s}$ the patient flexed their neck and expelled the lavage into a sterile container. The whole nasal lavage was dispersed with $0.1 \%$ DTT and processed as for sputum. Due to the nasal lavage being less cellular than the sputum a differential cell count of $>100$ cells was derived. Cell counts were performed by an experienced observer blind to clinical characteristics.

\section{Study design}

Subjects attended the respiratory function laboratory on four occasions. At the first visit the duration of cough, its severity assessed by VAS and the presence or absence of rhinitis defined as upper airway symptoms: coryza, postnasal drip and pain with tenderness over the paranasal sinuses together with evidence of nasal or pharyngeal mucosal inflammation were recorded. Cough reflex sensitivity was assessed by a capsaicin challenge. In the same week at the same time of day a standard histamine challenge test was performed incorporating both FEV1 and inspiratory flow volume loop measurements (MIF50). Induced sputum and a nasal wash were collected after recovery from the challenge. Subjects were then started on budesonide 400 $\mu \mathrm{g}$ inhaled via a turbohaler (AstraZeneca, Herfordshire, UK) twice daily for 4-weeks. The tests were repeated in the same sequence at the same time of day at two further visits at the end of treatment $2-4 \mathrm{~h}$ after the last dose of budesonide.

\section{Analysis}

Intrathoracic and extrathoracic responsiveness were expressed as the $\mathrm{PC} 20$ and $>25 \%$ reduction in MIF50 (PC25) respectively. Intra- and extrathoracic hyperresponsiveness were defined as $\mathrm{PC} 20$ and $\mathrm{PC} 25<8 \mathrm{mg} \cdot \mathrm{mL}^{-1}$. Histamine $\mathrm{PC} 20, \mathrm{PC} 25$, concentration required to cause two coughs $\left(\mathrm{C}_{2}\right)$ and five coughs $\left(\mathrm{C}_{5}\right)$ were calculated by linear 
Table 2. - Patient characteristics before and after inhaled budesonide

\begin{tabular}{|c|c|c|}
\hline & $\begin{array}{l}\text { Pre-inhaled } \\
\text { steroids }\end{array}$ & $\begin{array}{l}\text { Post-inhaled } \\
\text { steroids }\end{array}$ \\
\hline FEV1 \% pred $^{+}$ & $103 \pm 7$ & $110 \pm 9$ \\
\hline $\mathrm{FEV}_{1 / \mathrm{FVC}^{+}}$ & $80.5 \pm 1.5$ & $79.9 \pm 1.2$ \\
\hline Histamine $\mathrm{PC}_{2} 0<16 \mathrm{mg} \cdot \mathrm{mL}^{-1}$ & 0 & 0 \\
\hline Histamine $\mathrm{PC} 25<16 \mathrm{mg} \cdot \mathrm{mL}^{-1}$ & 2 & 2 \\
\hline $\mathrm{C}_{2}(\text { Capsaicin concentration } \mu \mathrm{M})^{\#}$ & $3.24(0.04)$ & $5.48(0.07)^{*}$ \\
\hline $\mathrm{C}_{5}$ (Capsaicin concentration $\left.\mu \mathrm{M}\right)$ & $14.1(0.10)$ & $34.4(0.11)^{*}$ \\
\hline Visual analogue scale $\mathrm{mm}^{+}$ & $27.7 \pm 6.6$ & $12.6 \pm 5.7^{*}$ \\
\hline \multicolumn{3}{|l|}{ Sputum characteristics } \\
\hline Eosinophil count \% $\#$ & $12.8(0.13)$ & $2.9(0.20)^{*}$ \\
\hline Neutrophil count \%** & $62(38)$ & $52(40)$ \\
\hline Macrophage count $\% * *$ & $25(20)$ & $40(31)$ \\
\hline locyte count $\% * *$ & $0(1)$ & $0(1)$ \\
\hline Epithelial count $\% * *$ & $1(1)$ & $2(4)$ \\
\hline Squamous cells $\% * *$ & $8(10)$ & $5(8)$ \\
\hline Viability cells \%** & $75(11)$ & $72(49)$ \\
\hline \multicolumn{3}{|l|}{ Total cell count } \\
\hline$\times 10^{6} \cdot \mathrm{mL}$ sputum & $2.2(0.10)$ & $1.9(0.09)$ \\
\hline
\end{tabular}

FEV1: forced expiratory volume in one second; FVC: forced vital capacity; PC20: provocative concentration of histamine causing a $20 \%$ in FEV1. PC25: provocative concentration causing a $>25 \%$ reduction in maximal mid-expiratory flow; $\mathrm{C}_{2}$ : capsaicin concentration required to cause two coughs; $\mathrm{C}_{5}$ : capsaicin concentration required to cause five coughs. ${ }^{+}$: mean $\pm \mathrm{SEM}$; ${ }^{\#}$ : geometric mean $(\log \mathrm{SEM}){ }^{*}: \mathrm{p}<0.05 ; * *$ : median (interquartile range);

interpolation of log dose response curve and were described as geometric means. Cough paroxysms of more than five coughs were not possible to quantify so a censored value of 10 coughs was assigned. Sputum eosinophil count and total cell count were log normally distributed and described as geometric mean (log SEM). Other sputum cell characteristics are described as median (interquartile range). Change in sputum eosinophil count was expressed as fold differences with $95 \%$ confidence intervals (CI) and change in $\mathrm{C}_{2}$ and $\mathrm{C}_{5}$ in doubling doses. The significance of changes were assessed using Student's paired t-test or Mann-Whitney U-test and correlation performed by Pearson's correlation coefficient.

\section{Results}

The geometric mean sputum eosinophil count did not significantly change from diagnosis, $13.2 \%$, to entry into the study, $12.8 \%$, (mean difference 1.03 -fold, $95 \%$ CI $0.6-$ $1.7 ; \mathrm{p}=0.8$ ). There was no significant difference in any other sputum cell count. The characteristics of the patients at the time of diagnosis are shown in table 1 and at baseline in table 2. Eosinophils were present in the nasal lavage of three patients, two of whom had a greater nasal than sputum percentage eosinophil count. This eosinophilic rhinitis improved after inhaled budesonide (fig. 1). Extrathoracic airway responsiveness was demonstrated in one of these patients. One further patient had extrathoracic hyperresponsiveness, but had nasal lavage evidence of a neutrophilic rhinitis. All of the subjects had normal lower airway responsiveness before and after inhaled budesonide with no significant change in the slope of the dose-response curve.
The changes after treatment with inhaled budesonide are summarized in table 2. Following treatment, the sputum eosinophil count decreased significantly from $12.8 \%$ to 2.9\% (mean difference 4.4-fold, 95\% CI 2.14-10.02; $\mathrm{p}<0.01$; fig. 1). The mean cough VAS was significantly reduced from $27.2 \mathrm{~mm}$ to $12.6 \mathrm{~mm}$ following treatment (mean difference $14.6 \mathrm{~mm}$; 95\% CI 20.1-9.1; $\mathrm{p}<0.01$ ). $\mathrm{C}_{2}$ increased from $3.3 \mu \mathrm{M}$ to $5.5 \mu \mathrm{M}$ and $\mathrm{C}_{5}$ from $14.1 \mu \mathrm{M}$ to $34.4 \mu \mathrm{M}$ after treatment $\left(\mathrm{C}_{2}\right.$ mean difference 0.75 doubling concentrations, $95 \%$ CI $0.36-1.1 ; \mathrm{p}<0.01 ; \mathrm{C}_{5}$ mean difference 1.3 doubling concentrations, $95 \%$ CI $0.6-2.1$; $\mathrm{p}<0.01 \%$ fig. 2). There was a significant correlation between the fold change in eosinophil count and the doubling concentration change in $\mathrm{C}_{5}$ after inhaled steroids $(\mathrm{r}=0.61 ; \mathrm{p}<0.05$; fig. 3$)$.

\section{Discussion}

This study has shown that upper airway inflammation and hyperresponsiveness are not prominent features of eosinophilic bronchitis. The authors have confirmed previous findings [2] that inhaled corticosteroids decrease the sputum eosinophil count and improve cough. The authors have extended these findings by showing objective evidence of improvement in capsaicin cough sensitivity following treatment.

Like other studies [2] evaluating the effect of treatment in patients with eosinophilic bronchitis, this study was uncontrolled. Eosinophilic bronchitis is a recently recognized condition, which although a common cause of chronic cough $[3,4]$, is not sufficiently prevalent to easily recruit for placebo controlled studies. Furthermore, the main focus of the current study was not the efficacy of treatment but the relative effects on upper and lower airway inflammation. The authors doubt whether the improvement in cough severity and sensitivity coupled with the marked decrease in sputum eosinophilia after treatment was due to regression towards the mean because the sputum eosinophil count did not significantly change from diagnosis at least 1 month before entry into the study. Laboratory assessments were performed blind

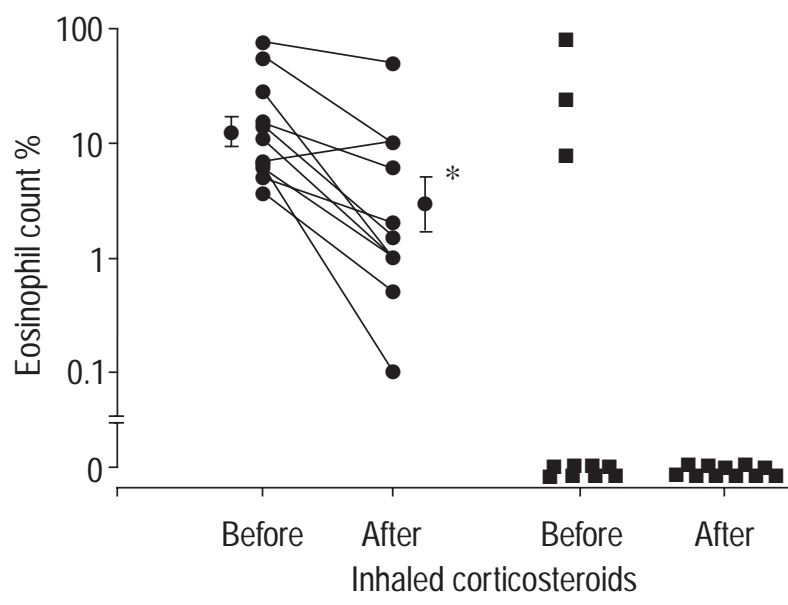

Fig. 1. - Sputum (O) and nasal lavage ( $\square$ ) eosinophil count before and after inhaled budesonide with sputum. Individual values and geometric mean \pm SEM are given. Normal range for sputum eosinophil count is 0 $1 \%$. * $\mathrm{p}<0.05$. 


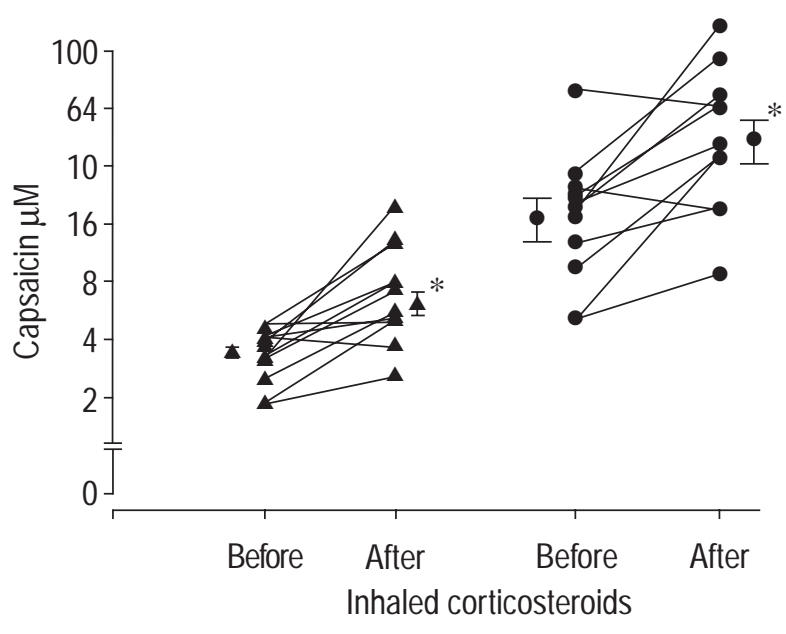

Fig. 2. - Capsaicin concentration causing two coughs ( $\boldsymbol{\Delta})$ and five coughs $(\mathbf{O})$ before and after inhaled budesonide. Individual values and geometric mean \pm SEM are given. $*$ : $\mathrm{p}<0.05$.

to patient's clinical characteristics and treatment so results are unlikely to have been biased.

The effect of a histamine challenge on sputum cell counts is unclear, but the study design was such that the relationship between the challenge and sputum induction was the same before and after treatment so any effect of histamine on cell counts would not have biased the results. Bronchial provocation with methacholine has been shown to have no effect on sputum cell characteristics [14] and histamine has been reported to result in no alteration in bronchial biopsy morphology or cellular infiltration [15]. However, $24 \mathrm{~h}$ after a histamine challenge there is an increase in the lymphocyte, mast cell and neutrophil count with no reported change in the eosinophil count in bronchoalveolar lavage [16]. In the current study the sputum induction was performed immediately after a histamine challenge. It is unlikely that histamine would have an immediate effect on the cell characteristics of sputum and in support of this there was no significant difference in the cellular characteristics of the subjects at diagnosis after methacholine compared with the study baseline after histamine.

The authors chose to test their hypothesis that eosinophilic bronchitis is predominantly due to upper airway inflammation by directly assessing inflammation using nasal wash differential cell count and looking for functional evidence by measuring upper airway responsiveness. BuccA et al. [7] have shown that a fall in inspiratory flow following a histamine challenge, known as extrathoracic hyperresponsiveness, corresponded with increased oedema, erythema and hypersecretion of the pharyngolaryngeal mucosa seen on laryngoscopy and was associated with upper airway inflammation such as rhinosinusitis and pharyngitis. Allergic rhinitis is typically associated with a nasal wash eosinophilia [5]. Upper airway hyperresponsiveness (demonstrated by a dose-related decrease in MIF50 during a histamine challenge) [6-8] has been shown to be associated with upper airway inflammation. Neither nasal wash eosinophilia or upper airway hyperresponsiveness were prominent in the current patients, in spite of upper airway symptoms being common, arguing against

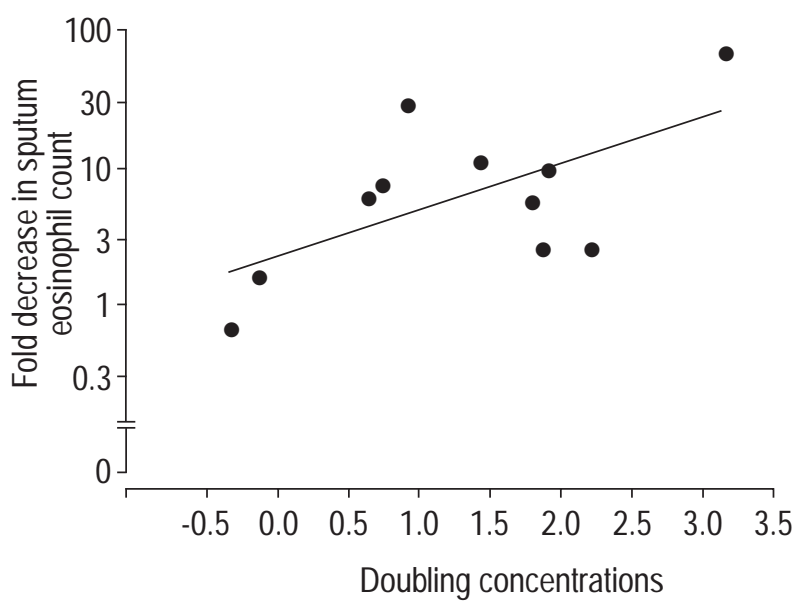

Fig. 3. - Correlation between fold decrease in sputum eosinophil count after treatment with inhaled budesonide and cough sensitivity assessed as the doubling fold increase in capsaicin concentration required to cause five coughs. $r=0.61, p<0.05$. Regression line is shown.

the authors' hypothesis. It is possible that inhaled corticosteroids improve upper airway inflammation and the effects of budesonide may have been mediated through this mechanism in some patients. The authors also cannot exclude the possibility that the eosinophilic airway inflammation is confined to another part of the upper airway, not directly sampled by nasal lavage. However, overall it is felt that the absence of predominant upper airway inflammation coupled with the presence of a sputum eosinophilia, which decreased with inhaled budesonide directed at the lower airway, is more in keeping with lower airway inflammation. A lower airway inflammation in eosinophilic bronchitis is further supported by the recent findings of a patient with eosinophilic bronchitis who had a bronchial wash eosinophilia [17].

If upper airway inflammation is not the reason for different functional associations in asthma and eosinophilic bronchitis then what is? It is possible that inflammation in eosinophilic bronchitis is predominantly in the small airways, or confined to a different part of the airway wall. Another possibility is that the eosinophilic airway inflammation is not as active in eosinophilic bronchitis with less release of bronchoconstrictor and airway damaging mediators such as histamine, cysteinyl-leukotrienes, prostanoids and eosinophilic cationic protein. Detailed comparison of the immunopathology of airway inflammation in eosinophilic bronchitis and asthma using bronchial biopsies and measurement of mediators from bronchial wash and induced sputum may help answer these questions. It has been suggested that eosinophilic airway inflammation in eosinophilic bronchitis does increase airway responsiveness, but within the normal range [18]. The current authors did not find a significant shift in the histamine dose response curve arguing against this view. However, the authors were not able to fully assess airway responsiveness as histamine is poorly tolerated in high doses. A more complete demonstration of the bronchoconstrictor dose-response curve would be possible using methacholine and this might increase the chance of showing treatment induced changes in airway responsiveness.

It was found that the capsaicin cough sensitivity was similar to previously reported asthmatics with chronic 
cough and more than asthmatics without chronic cough, patients with cough due to upper airway inflammation, postnasal drip and healthy control subjects [9]. Typically patients with eosinophilic bronchitis have a cough productive of scanty sputum in the morning [3] in keeping with a bronchitic component to their cough. The current findings suggest that heightened cough sensitivity might also contribute. Following inhaled corticosteroids the cough sensitivity improved and the degree of this improvement significantly correlated with the change in the sputum eosinophil count suggesting that eosinophilic airway inflammation is causally associated with enhanced cough reflex sensitivity.

In conclusion, it has been shown that upper airway inflammation and upper airway hyperresponsiveness are not prominent in eosinophilic bronchitis. This study has confirmed that inhaled corticosteroids improve cough severity, sensitivity and reduce the sputum eosinophil count and have shown that this is associated with a significant decrease in cough sensitivity. These findings support the presence of a lower airway inflammation in eosinophilic bronchitis. Further work is required to establish why an apparently similar airway inflammation is associated with such different abnormalities of airway function in eosinophilic bronchitis and asthma.

\section{References}

1. Gibson PG, Dolovich J, Denburg J, Ramsdale EH, Hargreave FE. Chronic cough: eosinophilic bronchitis without asthma. Lancet 1989; i : 1346-1348.

2. Gibson PG, Hargreave FE, Girgis-Gabardo, Morris M, Denburg JA, Dolovich J. Chronic cough with eosinophilic bronchitis: examination for variable airflow obstruction and response to corticosteroid. Clin Exp Allergy 1995; 25: 127-132.

3. Brightling CE, Ward R, Goh KL, Wardlaw AJ, Pavord ID. Eosinophilic bronchitis is an important cause of cough. Am J Respir Crit Care 1999; 160: 406-410.

4. Carney IK, Gibson PG, Murnee-Allen K, Saltos N, Olsen LG, Hensley MJ. A systematic evaluation of mechanisms in chronic cough. Am J Respir Crit Care Med 1997; 156: 211-216.

5. Bascom R, Pipkorn U, Lichtenstein LM, Naclerio RM. The influx of inflammatory cells into nasal washings during the late response to antigen challenge. Am Rev Respir Dis 1988; 138: 406-412.

6. Bucca C, Rolla G, Scappaticci E. Extrathoracic and intrathoracic responsiveness in sinusitis. $J$ Allergy Clin Immunol 1995; 95: 52-59.

7. Bucca C, Rolla G, Scappaticci E, Baldi S, Caria E, Oliva A. Histamine hyperresponsiveness of the extrathoracic airway in patients with asthmatic symptoms. Allergy 1991; 46: 147-153.

8. Bucca C, Rolla G, Brussino L, De Rose V, Bugiani M. Are asthma-like symptoms due to bronchial or extrathoracic airway dysfunction? Lancet 1995; 346: 791-795.

9. Choudry NB, Fuller RW. Sensitivity of the cough reflex in patients with chronic cough. Eur Resp J 1992; 5: 296300 .

10. O'Connell F, Thomas V, Pride N, Fuller RW. Capsaicin cough sensitivity decreases with successful treatment of chronic cough. Am J Respir Crit Care Med 1994; 150: 374-380.

11. Juniper EF, Cockcroft DW, Hargreave FE. Histamine and methacholine inhalation tests: a laboratory tidal breathing protocol. 2nd Edn. Lund, Sweden, Astra Draco AB, 1994.

12. Pizzichini E, Pizzichini MMM, Efthimiadis A, et al. Indices of airway inflammation in induced sputum: reproducibility and validity of cell and fluid phase measurements. Am J Respir Crit Care Med 1996; 154: 308-317.

13. Pavord ID, Pizzichini MMM, Pizzichini E, Hargreave FE. The use of induced sputum to investigate airway inflammation. Thorax 1997; 52: 498-501.

14. Spanevello A, Vignola AM, Bonanno A, Confalonieri M, Crimi E, Brusasco V. Effect of methacholine challenge on cellular composition of sputum induction. Thorax 1999; 54: $37-39$.

15. Soderberg M, Lundgren R, Hellstrom S, Horstedt P, Berg A. Bronchial mucosal structure after histamine inhalation. Allergy 1991; 48: 25-29.

16. Soderberg M, Lundgren R, Bjermer L, Stjernberg N, Rosenthall L. Inflammatory response in bronchoalveolar lavage fluid after inhaling histamine. Allergy 1989; 44: 98-102.

17. Brightling CE, Woltmann G, Wardlaw AJ, Pavord ID. The development of irreversible airflow obstruction in a patient with eosinophilic bronchitis without asthma. Eur Respir J; 1999; 14: 1228-1230.

18. Wong AG, Pavord ID, Sears MR, Hargreave FE. A case for serial examination of sputum inflammatory cells. Eur Respir J 1996; 9: 2174-2175. 